\title{
Precise Incubation Period for the Agrobacterium- mediated Transformation Efficiency in Potato (Solanum tuberosum L.) cvs. Cardinal and Atlas
}

\author{
S. R. Sarker*, M. Hossain and F. Shirin \\ Plant Breeding and Gene Engineering Laboratory, Department of Botany, \\ Rajshahi University, Rajshahi-6205, Bangladesh
}

Key words: Transformation, Incubation period, Potato cultivars

\begin{abstract}
Precise incubation period facilitates significant response to Agrobacteriummediated genetic transformation of potato (Solanum tuberosum L.) cvs. Atlas and Cardinal. The protocol yielded an average transformation rate of $58.4 \%$ for internodal explants compared to $38 \%$ for leaf explants in Atlas while $47.6 \%$ for intenodal explants as against $7.6 \%$ for leaf explants in Cardinal. Highest survival rate and transient GUS activity were shown by Atlas and Cardinal at $45 \mathrm{~min}$ of incubation with Agrobacterium. The plants were analyzed histochemically for GUS activity in their leaves and internodes. All these analysis indicated that each independently selected and regenerated plants of Atlas and Cardinal were GUS positive and transient.
\end{abstract}

\section{Introduction}

Potato (Solanum tuberosum L.) is one of the most agronomically and economically important plants in the world after rice, wheat and maize, notably due to its high productivity and its high starch, vitamin and protein content (Beaujean et al. 1998). Potato provides roughly half of the world's annual production of all root and tuber-based foods, making it the leading non-cereal crop. It is a part of the diet of half a billion consumers in the developing countries (Ghislain et al. 1999).

The production or yield of a crop can fall dramatically as a result of pathogen infection and renders a particular variety of crop no longer saleable or commercially viable. It is well-known that the apical meristems are generarally either free or carry a very low concentration of viruses. The apical meristems culture is the way to obtain a clone of virus free plant which can be multiplied vegetatively under controlled conditions that would protect them from chances of reinfecton (De 2001). However, this procedure is not applicable to other pathogens. Therefore, it is possible to develop virus free potato planting stocks

*Author for correspondence. < shiprasarker21@yahoo.co.in>. 
on a mass scale through meristem culture but not yet possible to develop fungal and bacterial resistant cultivars. Genetic engineering to crop agriculture has been targeted to produce transgenic plants expressing foreign genes that confer resistance to viruses, insects, herbicide or post harvest deterioration and accumulation of useful modified storage products (Chawla 2000). Genetic transformation facilitates introduction of only specifically desirable genes without co-transfer of any undesirable gene from donor species which normally occurs by conventional breeding methods. Therefore, establishment of reproducible and efficient Agrobacterium-mediated genetic transformation methods have assumed an increasing importance for further potato improvement. In Solanum, genetic transformation by various disarmed Agrobacterium tumefaciens strains has been the most successful and widely used approach compared to other methods (Sheerman and Bevan 1988, Stiekema et al. 1988, Visser et al. 1989, Wenzler et al. 1989, Conner et al. 1991, Vayda and Belknap 1992, Lecarddonnel et al. 1999, Tobias et al. 1999). Transgenic potato plants are generated worldwide to assess the impact of transgenic expression on parameters as diverse as yield, quality, altered stress physiology, and pest or disease resistance. New traits have been introduced into potato cultivars such as PVX virus resistance (Hemenway et al. 1988, Hoekema et al. 1989, Lawson et al. 1990), soft rot and wilt resistance (Düring et al. 1993, Jaynes et al. 1993), potato tuber moth and Colorado potato beetle resistance (Peferoen et al. 1990, Adang et al. 1993, Perlak et al. 1993), increased starch content (Stark et al. 1992), human serum albumin and cyclodextrin production (Sijmons et al. 1990, Oakes et al. 1991) etc.

One of the main considerations for any gene transfer is the potential of the recipient cell to express the introduced gene. Stable transformation occurs when a specific DNA segment is integrated into the plant nuclear or plasmid genomes, followed by its expression in regenerated plants and is inherited in subsequent generations (Chawla 2000). In order to apply gene technology successfully, it is essential to establish a suitable protocol for further transgene expression. In our study the main consideration was the implementation of gene technology for establishing pathogen resistance in local agronomical field where the potato cultivars Atlas and Cardinal had a huge impact on market value.

\section{Materials and Methods}

Leaf and internodal explants of potato (Solanum tuberosum L.) cvs. Atlas and Cardinal excised from three - four weeks old shoot cultures were used for the experiments.

Agrobacterium strain and plasmid: Agrobacterium tumefaciens strain LBA4404 (pVDH65, pTOK47) designated 1065 was used (Curtis et al. 1994). LBA4404 (1065) contained the binary vector pVDH65 and a supervirulent plasmid 
pTOK47 (Jin et al. 1987). The binary vector pVDH65 (Fig. 1), based on the pBIN19 derivative pMOG18 carried a T-DNA with the chimeric nos.nptII.nos and introngus genes and was received from CAMBIA.

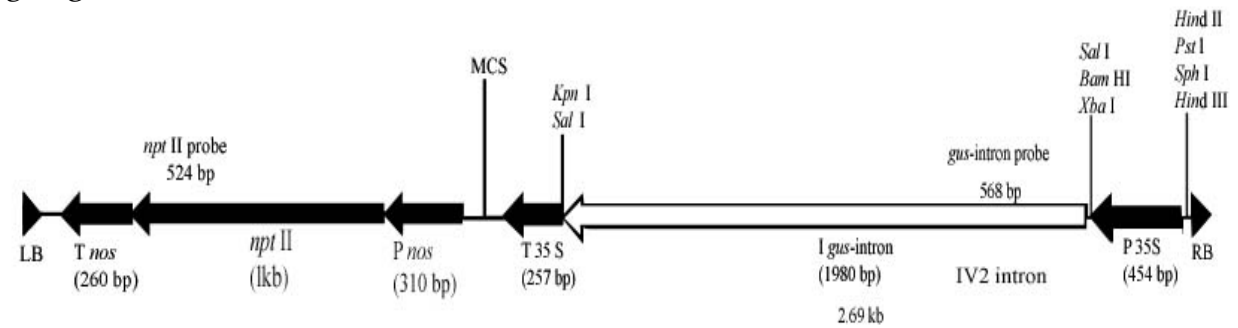

Fig. 1. pVDH65.

Cultures were grown at $20^{\circ} \mathrm{C}$ in a $16 \mathrm{hr}$ light $\left(60 \mu \mathrm{E} \mathrm{m} \mathrm{m}^{2}\right.$; cool white fluorescent tubes) period. All plant media were adjusted with $1 \mathrm{~N} \mathrm{NaOH}$ to $\mathrm{pH}$ 5.7, solidified with $8 \mathrm{~g} / \mathrm{l}$ agar and autoclaved at $121^{\circ} \mathrm{C}$ for $20 \mathrm{~min}$.

The sensitivity of potato leaf and internodes to kanamycin was assayed by culturing them with A. tumefaciens without co-cultivation on the selection medium containing different concentrations of kanamycin $(0,25,50,75$ and 100 $\mathrm{mg} / \mathrm{l})$.

Leaf and internodal explants excised from three - four weeks old in vitro plants were cut into pieces $\left(2 \mathrm{~mm}^{2}\right.$ each). Explants were inoculated with $A$. tumefaciens cells harbouring LBA4404 (1065). They had both nptII- and GUS gene in liquid MS0 medium supplemented with $100 \mathrm{mg} / \mathrm{l}$ kanamycin for 15 - $75 \mathrm{~min}$ (each at $15 \mathrm{~min}$ interval). Subsequently, the density of Agrobacterium inoculums of $0.50-2.50$ at $600 \mathrm{~nm}$ and co-cultivation for $12-72 \mathrm{~h}$ on agar gelled MS0 medium. After co-cultivation, the explants were transferred and placed upside down on to the selection and regeneration medium (MS $+0.20 \mathrm{mg} / \mathrm{l} \mathrm{NAA}+0.02$ $\mathrm{mg} / \mathrm{l} \mathrm{GA} 3+2 \mathrm{mg} / \mathrm{l}$ zeatin $+100 \mathrm{mg} / \mathrm{l} \mathrm{kanamycin}+250 \mathrm{mg} / \mathrm{l}$ cefotaxime) and inoculated under light. After four weeks shoot formed at the cut end of the leaf discs and internodes and transferred onto same fresh medium for shoot induction. Kanamycin resistant shoots were separated and transferred to MS supplemented with $100 \mathrm{mg} / \mathrm{l}$ kanamycin for shooting.

The presence of transgenes in transformed and control plants was analyzed by the polymerase chain reaction (PCR). Genomic DNA of potato was extracted from young leaves following the protocol of Edwards et al. 1991. PCR analyses to detect the presence of nptII gene were carried using the PCR Screening Kit (Sigma Chemical Ltd., USA) in the presence of following pair of primers: forward primer (5-GTTGCTCTCAAGGGACTTGC-3) and reverse primer (5CACACACCGTGACCCTTTC-3). The PCR mixtures were denatured at $94^{\circ} \mathrm{C}$ for $4 \mathrm{~min}$ followed by $35 \mathrm{cycles}$ for $1 \mathrm{~min}$ at $94^{\circ} \mathrm{C}, 1 \mathrm{~min}$ at $58^{\circ} \mathrm{C}$ for annealing, 1.30 min at $72^{\circ} \mathrm{C}$ for extension and finally incubated at $72^{\circ} \mathrm{C}$ for $10 \mathrm{~min}$. Expected PCR 
product size was about 365 bps. Amplified cDNA were resolved on $1.5-2 \%$ agarose gel, stained with ethidium bromide (EtBr) and documented.

\section{Results and Discussion}

To establish a rapid and efficient Agrobacterium-mediated transformation method for potato, the action of different concentrations of antibiotics that were used as selectable markers in plant transformation was assayed. One hundred mg/l kanamycin completely blocked regeneration from untransformed explants and, therefore, could be used to select for transformed cells. The callus and shoot regeneration media used in the present studies contained zeatin in addition to NAA and GA3. The highest percentage of explants showing regeneration was noticed with $\mathrm{MS}+0.20 \mathrm{mg} / \mathrm{l} \mathrm{NAA}+0.02 \mathrm{mg} / \mathrm{l} \mathrm{GA}+2 \mathrm{mg} / \mathrm{l}$ zeatin. The use of zeatin as a cytokinin in the culture media allowed rapid induction of large number of buds. Further evidence of the role of zeatin in controlling the development of highly organogenic micro calli has been provided by Beaujean et al. (1998) and Trujillo et al. (2001). GUS activity of leaf and internodal explants of both cultivars were investigated in turns of time such as 7, 14 and 21 days after culture on the selection medium. Data regarding kanamycin resistant/GUS ${ }^{+}$ plants were collected in five different experiments for both leaf and internodal explants of cvs. Atlas and Cardinal (Table 1).

Table 1. Transformation frequency of leaf and internodal explants of cvs. Atlas and Cardinal after inoculation with $A$. tumefaciens strain LBA4404 (1065).

\begin{tabular}{lccccc}
\hline & \multicolumn{2}{c}{ Atlas } & & \multicolumn{2}{c}{ Cardinal } \\
\cline { 2 - 3 } \cline { 5 - 6 } \cline { 5 - 6 } & Internode & Leaf & & Internode & Leaf \\
\hline Mean GUS $/$ Kana R $^{*}$ plants & 29.2 & 19 & & 23.8 & 13.8 \\
Mean transformation frequency & $58.4 \pm 5.42^{* * *}$ & $38 \pm 5.21$ & & $47.6 \pm 5.12^{* * *}$ & $27.6 \pm 4.63$ \\
\hline
\end{tabular}

Figures followed by ${ }^{* * *}$ differ at $\mathrm{p}>0.001$ level of significance as calculated by the ' $\mathrm{t}^{\prime}$ test. Kana $R^{*}$ : Kanamycin resistant, GUS+ ${ }^{+}$GUS positive.

Comparison of transformation frequency of both the cultivars revealed that internodal explants of both cultivars (58.4 \pm 5.42 and $47.6 \pm 5.12 \%$, respectively) were significantly $(\mathrm{p}<0.001)$ greater than from leaf explants $(38 \pm 5.21$ and $27.6 \pm$ $4.63 \%$, respectively). Moreover, both internodal (58.4 $\pm 5.42 \%)$ and leaf explants $(38 \pm 5.21 \%)$ of Atlas also showed significantly $(\mathrm{p}<0.01)$ higher values than internodal $(47.6 \pm 5.12 \%)$ and leaf explants $(27.6 \pm 4.63 \%)$ of Cardinal. Most of the published protocols for internode potato transformation used whole internodes (Ooms et al. 1987, Visser et al. 1989). Although internodal transformation is not frequently used, other reports (Gleadle 1992, working with dihaploid Solanum tuberosum material; Beaujean et al. 1998; working with Désirée, Bintje and Kaptah Vandel) confirmed that these explants are the most responsive explants for 
potato transformation. Moreover, the leaf explants were easily injured during the manipulation which resulted in a low percentage of transformation (De 1988) while the internodal explants are much more resistant during manipulation and more amenable to in vitro conditions.

The experiment was set to standardize the incubation time of explants cvs. Atlas and Cardinal with A. tumefaciens (Table 2). The survival rates of GUS positive leaf and internodal explants of both cultivars were observed to be optimized at incubation periods of $45 \mathrm{~min}$. At optimum incubation time the survival rates and transient GUS activity of $\mathrm{cv}$. Atlas were significantly higher ( $\mathrm{p}$ $<0.001$ ) in internodal explants ( $91 \pm 5.63$ and $72 \pm 7.66 \%$, respectively) than leaf explants (68 \pm 6.32 and $47 \pm 9.22 \%$, respectively). Similarly, at that peak, Cardinal showed better performance on survival rates and transient GUS activity ( $p<$ 0.001 ) for internodal explants ( $82 \pm 7.12$ and $63 \pm 5.60 \%$, respectively) than leaf explants (51 \pm 8.22 and $30 \pm 5.89 \%$, respectively). Both explants of Atlas had better response to transgene expression than that of Cardinal at $45 \mathrm{~min}$ incubation with $A$. tumefaciens. A transformation frequency over $90 \%$ was obtained at $30 \mathrm{~min}$ incubation period on internodal explants in three potato varieties, namely Bintje, Désirée and Kaptah Vandel (Beaujean et al. 1998). Both internodes and leaf discs of potato cultivar Desiree and Norkotah performed best for transformation at 15 - $30 \mathrm{~min}$ inoculation with A. tumefaciens (Arif et al. 2009). Similarly $30 \mathrm{~min}$ inoculation with $A$. tumefaciens was the best for transformation in both petiole-attached cotyledons and cotyledonary nodes and $60 \mathrm{~min}$ in mature embryos of two jute cultivars (Sarker et al. 2008). An infection period of 50 min with Agrobacterium was found to be optimum for the leaf, nodal and internodal explants in two potato varieties Lal Pakri and Jam Alu (Sarker and Mustafa 2002).

Table 2. Effect of incubation time on transient GUS activity in leaf and internodal explants of potato cvs. Atlas and Cardinal.

\begin{tabular}{|c|c|c|c|c|}
\hline \multirow{3}{*}{$\begin{array}{l}\text { Incubation time (min) } \\
\text { with A. tumefaciens }\end{array}$} & \multicolumn{4}{|c|}{ Percentage of GUS positive explants } \\
\hline & \multicolumn{2}{|c|}{ Atlas } & \multicolumn{2}{|c|}{ Cardinal } \\
\hline & Internode & Leaf & Internode & Leaf \\
\hline 15 & $29 \pm 5.51$ & $13 \pm 3.41$ & $20 \pm 8.83$ & $9 \pm 3$ \\
\hline 30 & $36 \pm 5.03$ & $27 \pm 5.63$ & $29 \pm 6.88$ & $19 \pm 6.88$ \\
\hline 45 & $72 \pm 7.66^{* * *}$ & $47 \pm 9.22$ & $63 \pm 5.60^{* * *}$ & $30 \pm 5.89$ \\
\hline 60 & $23 \pm 3.41$ & $10 \pm 2.58$ & $17 \pm 4.76$ & $8 \pm 3.65$ \\
\hline 75 & $11 \pm 4.43$ & $7 \pm 3.41$ & $9 \pm 4.12$ & $5 \pm 2.71$ \\
\hline
\end{tabular}

Figures followed by ${ }^{* * *}$ differ at $\mathrm{p}<0.001$ level of significance as calculated by the ' $t$ ' test.

PCR analysis using nptII specific primers was performed on 20 putatively transformed plants. Transformed plants displayed a $365 \mathrm{bp}$ amplification product which was missing in non-transformed control plants (Fig. 3). 

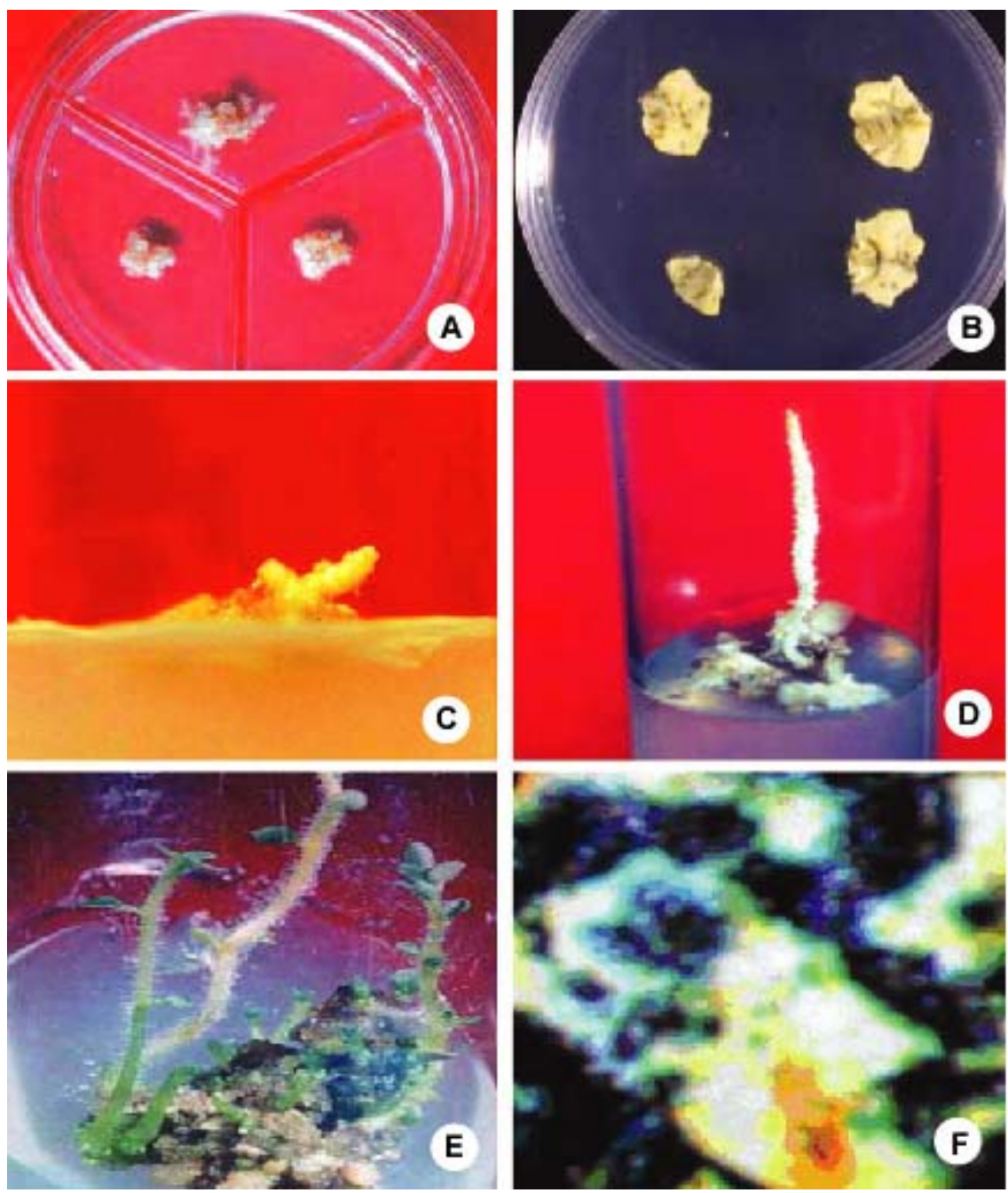

Fig 2. A. Co-cultivated leaf explants of Atlas (three weeks after inoculation). B. Non co-cultivated leaf explants of Atlas (three weeks after inoculation). C. Shoot regeneration from putative transformed leaf explants of Atlas (five weeks after culture). D. Shoot regeneration from putative transformed leaf explants of Cardinal (six weeks after culture). E. Shoot regeneration from putative transformed internodal explants of Atlas (eight weeks after culture). F. GUS activity in leaf explants five days after infection/co-cultivation following staining with 5-bromo-4-chloro-3-indolyl- $\beta$-D-glucuronic acid (X-Gluc).

Atlas and Cardinal are the most important potato varieties in Bangladesh especially for its production and taste quality. However, they are mostly affected by the viral, bacterial and fungal diseases with the reduction of productivity. Therefore, Agrobacterium-mediated genetic transformation is one of the best solutions for recovering precise tuber growth of potatoes with low financial support in a developing country like Bangladesh. The present study describes a 
short duration, reproducible and efficient protocol for production of transgenic plants of potato cultivars Atlas and Cardinal with the nptII gene as a selectable marker gene and GUS gene as a reporter gene. In the present investigation the highest transformation frequency of potato cvs. Atlas and Cardinal has been found at $45 \mathrm{~min}$ incubation with A. tumefaciens.

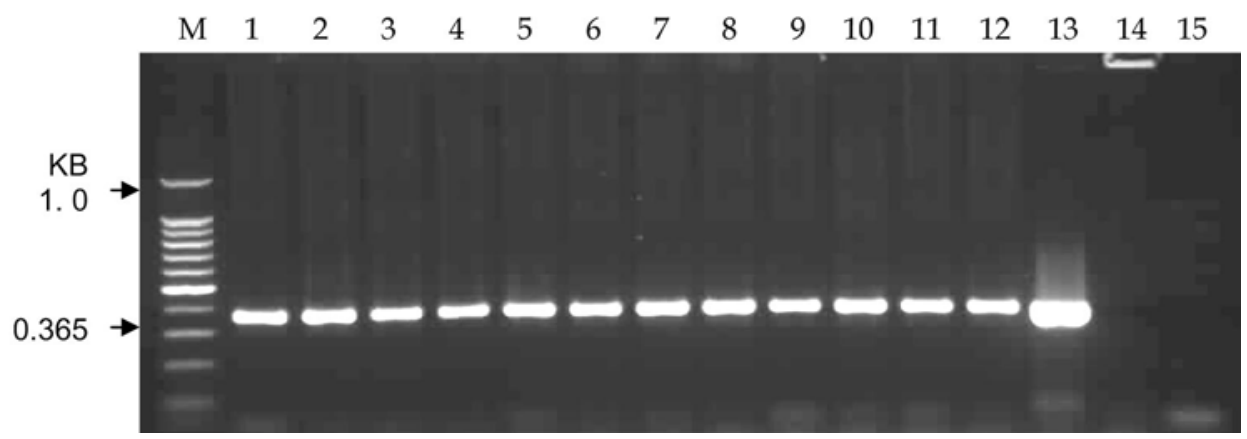

Fig. 3. PCR analysis of genomic DNA of potato (cv. Atlas). M: 100-bp size marker (Promega). Lanes 1-12: Plants regenerated from infected leaves showing expected 365bp band. Lane 13: Plasmid control. Lane 14: Control plant regenerated from uninfected leaf culture. Lane 15: Water (control).

\section{References}

Adang MJ, Brody MS, Cardineau G, Eagan N, Roush RT, Shewmaker CK, Jones A, Oakes JV and McBride KE (1993) The reconstruction and expression of a Bacillus thuringiensis cryШA gene in protoplasts and potato plants. Plant Mol. Biol. 21: 11311145.

Arif M, Thomas PE, Crosslin JM and Brown CR (2009) Agrobacterium-mediated transformation of potato using PLRV-REP and PVY CP genes and assessment of replicase mediated resistance against natural infection of PLRV. Pakistan J Bot. 41 (3):1477-1488.

Beaujean A, Sangwan RS, Lecardonnel A and Sangwan BS-Norrel (1998) Agrobacteriummediated transformation of three economically important potato cultivars using sliced internodal explants: an efficient protocol of transformation. J. Exp. Bot. 49: 1589-1595.

Curtis IS, Power JB, Blackhall NW, de Laat AMM and Davey MR (1994) Genotype independent transformation of lettuce using Agrobacterium tumefaciens. J Exp. Bot. 45: 1441-1449.

Chawla HS (2000) Transgenics in Crop Improvement In: Introduction to Plant Biotechnology, H S Chawla (Eds), Oxford \& IBH Publishing, Primlani, New Delhi, pp. 302-326.

Conner AJ, Williams MK, Gardner RC, Deroles SC, Shaw ML and Lancaster JE (1991) Agrobacterium-mediated transformation of New Zealand potato cultivars. New Zealand J. Crop and Hort. Sci. 19: 1-8. 
De Block M (1988) Genotype-independent leaf disc transformation of potato (Solanum tuberosum) using Agrobacterium tumefaciens. Theor. and Appl. Genet. 76: 767-774.

De KK (2001) Application and Importance of Plant Cell and Tissue Culture in Plant Science In: An Introduction to Plant Tissue Culture, Kalyan Kumar De (Eds), New Central Book Agency (P), Calcutta, pp. 178-185.

Düring K, Porsch P, Fladung M and Lörz H (1993) Transgenic potato plants resistant to the phytopathogenic bacterium Erwinia carotovora. Plant J. 3: 587-598.

Edwards K, Johnstone C and Thompson C (1991) A simple and rapid method for the preparation of plant genomic DNA for PCR analysis. Nucl. Acids Res. 19: 1349.

Ghislain M., Bonierbale M. and Nelson R (1999) Gene technology for potato in developing countries. In: Biotechnology of Food Crops in Developing Countries. Hohn T and Leisinger KM. (Eds.), Springer Verlag Wien, New York. pp. 105-140.

Gleadle AE (1992) Towards improvement of potato by genetic manipulation of dihaploid Solanum tuberosum. Ph.D. Thesis, Nottingham University, UK.

Hemenway C, Fang RX, Kaniewski WK, Chua NH and Tumer NE (1988) Analysis of the mechanism of protection in transgenic plants expressing the potato virus $X$ coat protein or its antisense RNA. The EMBO J. 7: 1273-1280.

Hoekema A, Huisman MJ, Molendijk L, van den Elzen PJM and Cornelissen BJC (1989) The genetic engineering of two commercial potato cultivars for resistance to potato virus X. Biotechnology 7 : 273-278.

Jaynes JM, Nagpala P, Destefano-Beltran L, Huang JH, Kim J, Denny T and Cetiner S (1993) Expression of a cecropin B lytic peptide analog in transgenic tobacco confers enhanced resistance to bacterial wilt caused by Pseudomonas solanacearum. Plant Sci. 89: 43-53.

Jin S, Komari T, Gordon MP and Nester EW (1987) Genes responsible for the super virulence phenotype of Agrobacterium tumefaciens A 281. J. Bacteriol. 169: 4417-4425.

Lawson C, Kaniewski W, Haley L, Rozman R, Newell C, Sanders P and Tumer NE (1990) Engineering resistance to mixed virus infection in a commercial potato cultivar: resistance to potato virus $\mathrm{X}$ and potato virus $\mathrm{Y}$ in transgenic Russet Burbank. Biotechnology 8: 127-134.

Lecardonnel A, Chauvin L, Jouanin L, Beaujean A, Prevost G and Sangwan B- Norrel (1999) Effects of rice cystatin 1 expression in target potato on Colorado potato beetle larvae. Plant Sci. 140: 71-79.

Oakes JV, Shewmaker CK and Stalker DM (1991) Production of cyclodextrins, a novel carbohydrate in the tubers of transgenic potato plants. Biotechnology 9: 982-986.

Ooms G, Burrell MM, Karp A, Bevan M and Hille J (1987) Genetic transformation in two potato cultivars with T-DNA From disarmed Agrobacterium. Theor. Appl. Genet. 73: 744-750.

Peferoen M, Jansens S, Reynaerts A and Leemans J (1990) Potato plants with engineered resistance against insect attack. In: The Molecular and Cellular Biology of the Potato, M.E. Vayda and W.D. Park (Eds.). CAB International, Wallingford, pp: 193-204.

Perlak FJ, Stone TB, Muskopf YM, Petersen LJ, Parker GB, McPheson SA, Wyman J, Love S, Reed G, Biever D and Fischhoff DA (1993) Genetically improved potatoes: protection from damage by Colorado potato beetles. Plant Mol. Biol. 22: 213-221. 
Sarker RH, Al-Amin GM, Hassan F and Hoque MI (2008) Agrobacterium-mediated genetic transformation of two varieties of jute (Corchorus capsularis L.). Plant Tissue Culture and Biotechnology 18(1): 7-16.

Sarker RH and Mostafa Barkat Murtaja (2002) Regeneration and Agrobacterium- mediated transformation of two indigenous potato varieties of Bangladesh. Plant. Tissue Cult. 12(1): 69-77.

Sheerman S and Bevan MW (1988) A rapid transformation method for Solanum tuberosum using binary Agrobacterium tumefaciens vectors. Plant Cell Rep. 7: 13-16.

Sijmons PC, Dekker BMM, Schrammeijer B, Verwoerd TC, van den Elzen PJM and Hoekema A (1990) Production of correctly processed human serum albumin in transgenic plants. Biotechnology 8: 217-221.

Stark DM, Timmerman KP, Barry GF, Preiss J and Kishore GM (1992) Regulation of the amount of starch in plant tissues by ADP glucose pyrophosphorylase. Sci. 258: 287292.

Stiekema WJ, Heidekamp F, Louwerse JD, Verhoeven HA. and Dijkhuis P (1988) Introduction of foreign genes into potato cultivars Bintje and Désirée using an Agrobacterium tumefaciens binary vector. Plant Cell Rep. 7: 47-50.

Tobias DJ, Hirose T, Ishimaru K, Ishige T, Ohkawa Y, Kano Y-Murakami, Matsuoka M and Ohsugi R (1999) Elevated sucrose-phosphate synthase activity in source leaves of potato plants transformed with the maize SPS gene. Plant Prod. Sci. 2: 92-99.

Trujillo C, Rodriguez E-Arangp, Jaramillo S, Hoyos R, Orduz S and Arango R (2001) One-step transformation of two Andean potato cultivars (Solanum tuberosum L. sub. sp. andigena ). Plant Cell Reports. 20: 637-641.

Vayda ME and Belknap WR (1992) The emergence of transgenic potatoes as commercial products and tools for basic research. Transgenic Research 1: 149-163.

Visser RGF, Jacobsen E, Hesseling-Meinders A, Schans MJ, Witholt B and Feenstra WJ (1989) Transformation of homozygous diploid potato with an Agrobacterium tumefaciens binary vector system by adventitious regeneration on leaf and stem segments. Plant Mol. Biol. 12: 329-337.

Wenzler H, Mignery G, May G and Park W (1989) A rapid and efficient transformation method for the production of large numbers of transgenic potato plants. Plant Sci. 63: 79-85. 